\title{
ĐÁNH GIÁ TìNH HìNH NGộ ĐộC THỰC PHẨM TẠI BÀ RỊA - VŨ̃NG TÀU GIAI ĐOẠN 2016 - 2018
}

\author{
Tiêu Văn Linh*, Đinh Thị Ngân \\ Chi cục An toàn vệ sinh thục phẩm tỉnh Bà Rịa - Vũng Tàu \\ (Ngày đến tòa soạn: 24/5/2019; Ngày sủa bài sau phản biện: 16/8/2019; \\ Ngày chấp nhận đăng: 6/9/2019)
}

\section{Tóm tắt}

Ngộ độc thực phẩm luôn có xu hướng diễn biến phức tạp và để lại các hậu quả nghiêm trọng đến sức khỏe người tiêu dùng. Bài báo cáo này tiến hành nghiên cứu hồi cứu các vụ NĐTP tại Bà Rịa -Vũng Tàu từ năm 2016 đến năm 2018, từ đó làm cơ sở cho việc hoạch định chiến lược, chương trình hành động phù hợp cho sự can thiệp mang tính khoa học khách quan trong công tác quản lý nhà nước về vệ sinh an toàn thực phẩm trên địa bàn tỉnh Bà Rịa - Vũng Tàu.

Kết quả nghiên cứu tình hình ngộ độc thực phẩm tỉnh Bà Rịa - Vũng Tàu giai đoạn 2016 đến 2018 cho thấy trung bình mỗi năm có 03 vụ ngộ độc thực phẩm với 68 người mắc và 01 người tử vong. Nguyên nhân gây ngộ độc thực phẩm nhiều nhất là do vi sinh vật với tỷ lệ $72,41 \%$, kế đến là do thuốc bảo vệ thực vật chiếm $21,83 \%$ và thấp nhất là do độc tố tự nhiên với tỷ lệ $5,74 \%$. Các vụ ngộ độc thực phẩm thường xảy ra tại các gia đình (chiếm tỷ lệ $55,56 \%$ ), các bếp ăn tập thể $(22,22 \%)$ và các nhà hàng ăn uống $(22,22 \%)$.

Tù khóa: Ngộ độc thưc phẩm, số vu ngộ độc thực phẩm, an toàn vệ sinh thưc phẩm, Bà RịaVüng Tàu.

\section{1. ĐẠT VẤN ĐỀ}

An toàn vệ sinh thực phẩm (ATVSTP) là một vấn đề được nhiều quốc gia trên thế giới rất quan tâm, mỗi quốc gia đều xây dựng chiến lược, chính sách toàn diện về an ninh lương thực, ATVSTP cho sự phát triển của đất nước và sự phát triển giống nòi. Tại Việt Nam, với xu thế hội nhập kinh tế quốc tế thì vấn đề ATVSTP càng làm cho các nhà quản lý, các nhà chuyên môn và toàn xã hội quan tâm, không ngừng ý thức việc cung cấp thực phẩm an toàn cho người tiêu dùng và cộng đồng xã hội. Trong đó, để bảo đảm ATVSTP cần quan tâm hàng đầu vào các vấn đề sau: Khối lượng thực phẩm cung cấp cho con người, chất lượng thực phẩm phải được bảo đảm, sự phát triển các ngành nghề trong chăn nuôi, trồng trọt, khai thác, thu hoạch, bảo quản, sản xuất, chế biến, lưu thông phân phối cũng được đầu tư về nhiều mặt như kinh phí, kỹ thuật, diện tích nuôi trồng, nhân lực có trình độ, nghiên cứu khoa học cũng là một nhân tố rất quan trọng.

Hậu quả cuối cùng của việc không bảo đảm an toàn thực phẩm (ATTP) là gây ra ngộ độc thực phẩm (NĐTP) và các bệnh truyền qua thực phẩm. Trong giai đoạn 2011 - 2016, toàn quốc đã ghi nhận 1.007 vụ NĐTP với 30.395 người mắc và 164 người chết. Trung bình có 167,8 vụ/năm với $5.065,8$ người mắc/năm và 27,3 người chết do NĐTP/năm. So với trung bình giai đoạn 2006-2010, số vụ NĐTP giảm 22 vụ (11,6\%), số người mắc giảm 1.567 người $(23,6 \%)$, số người tử vong giảm 25 người $(47,5 \%)[2]$. 
Nguyên nhân gây NĐTP chủ yếu do vi sinh vật (chiếm 40,2\%), tiếp đến nguyên nhân do độc tố tự nhiên chiếm $27,9 \%$, do hoá chất chiếm $4,3 \%$ và còn 268 vụ không xác định được nguyên nhân gây ngộ độc (chiếm tỷ lệ 26,6\%) [2].

NĐTP gây ảnh hưởng nghiêm trọng đến sức khỏe của con người, nếu không được điều trị kịp thời có thể dẫn đến tử vong. Chủ động phòng, chống NĐTP là trách nhiệm và đòi hỏi sự chung tay của toàn xã hội. Các cơ quan quản lý nhà nước về ATTP phải tăng cường các biện pháp bảo đảm ATTP để góp phần phòng tránh NĐTP, bệnh truyền qua thực phẩm cho cộng đồng.

\section{PHƯƠNG PHÁP NGHIÊN CÚU}

\section{1.Đối tượng nghiên cứu}

Các vụ NĐTP tại tỉnh Bà Rịa - Vũng Tàu (BR-VT) qua các năm 2016, 2017, 2018.

\subsection{Thiết kế nghiên cứu}

Nghiên cứu hồi cứu các vụ NĐTP tại BR-VT từ năm 2016 đến năm 2018.

\subsection{Cõ̃ mẫu và phương pháp chọn mẫu}

Tất cả các vụ NĐTP trong 03 năm từ năm 2016 đến 09 tháng năm 2018 đều được chọn để thống kê phân tích.

\subsection{Phương pháp thu thập dữ liệu}

Sử dụng mẫu 2 ban hành kèm theo Quyết định số 01/2006/QĐ-BYT ngày 09/01/2006 của Bộ trưởng Bộ $\mathrm{Y}$ tế về việc ban hành "Quy định chế độ báo cáo và mẫu báo cáo về vệ sinh an toàn thực phẩm" bao gồm số vụ, số người mắc, số người tử vong, quy mô, hoàn cảnh, căn nguyên và phân bố theo thời gian, địa điểm của các vụ NĐTP.

\subsection{Phương pháp phân tích và xử lý số liệu}

Số liệu được nhập và phân tích bằng phần mềm Excel, thống kê mô tả sử dụng trong nghiên cứu là tần số, tỷ lệ \%.

\section{KẾT QUẢ NGHIÊN CÚ'U}

\subsection{Số vụ NĐTP, số người mắc NĐTP giai đoạn 2016 - 2018}

Trong giai đoạn 2016-2018, tỉnh BR-VT xảy ra tổng cộng 09 vụ NĐTP với 204 người mắc, số người tử vong là 03 người. Trung bình là 03 vụ/năm, 68 người mắc/năm, số tử vong là 01 người/năm, cụ thể qua bảng sau:

Bảng 1. Số vụ ngộ độc thực phẩm giai đoạn 2016 - 2018

\begin{tabular}{|c|c|c|c|c|}
\hline Năm & $\mathbf{2 0 1 6}$ & $\mathbf{2 0 1 7}$ & $\mathbf{2 0 1 8}$ & Tổng cộng \\
\hline Số vụ & 02 & 06 & 01 & 09 \\
\hline Số người mắc & 10 & 167 & 27 & 204 \\
\hline
\end{tabular}

Tỷ lệ NĐTP giai đoạn 2016-2018 của tỉnh so với cả nước chiếm 2,73\% số vụ, 2,13\% số người mắc và $6,52 \%$ số tử vong. Tỷ lệ NĐTP của tỉnh có số vụ, số người mắc thấp hơn và có số tử vong cao hơn so với nghiên cứu của Đoàn Lê Thanh Phong về Đặc điểm dịch tễ các vụ NĐTP tại Tiền Giang từ năm 2006 đến năm 2015 với 7,9 vụ/năm, 358,9 người mắc/năm, số tử vong là 0,8 người/năm [13].

\subsection{Nguyên nhân gây ngộ độc thực phẩm giai đoạn 2016 - 2018}

Nguyên nhân gây NĐTP được chia thành ba nhóm: Do vi sinh vật, do độc tố tự nhiên và do hóa chất. Tại tỉnh BR-VT, tỷ lệ các nguyên nhân gây NĐTP được thể hiện qua bảng sau: 
Bảng 2. Tỷ lệ các nguyên nhân gây NĐTP giai đoạn 2016 - 2018

\begin{tabular}{|c|c|c|c|c|c|c|c|c|c|}
\hline \multirow[b]{2}{*}{$S T T$} & \multirow[b]{2}{*}{ Nguyên nhân } & \multicolumn{2}{|c|}{2016} & \multicolumn{2}{|c|}{2017} & \multicolumn{2}{|c|}{2018} & \multicolumn{2}{|c|}{ Giai doạn } \\
\hline & & $\begin{array}{c}\text { Số } \\
\text { ngưò̀i } \\
\text { mắc }\end{array}$ & $\begin{array}{l}\text { Tỉ lệ } \\
\text { (\%) }\end{array}$ & $\begin{array}{c}\text { Số } \\
\text { ngưò̀i } \\
\text { mắc }\end{array}$ & $\begin{array}{l}\text { Tỉ lệ } \\
\text { (\%) }\end{array}$ & $\begin{array}{c}\text { Số } \\
\text { người } \\
\text { mắc }\end{array}$ & $\begin{array}{l}\text { Tỉ lẹ } \\
\text { (\%) }\end{array}$ & $\begin{array}{c}\text { Số } \\
\text { người } \\
\text { mắc }\end{array}$ & $\begin{array}{l}\text { Tỉ lẹ } \\
\text { (\%) }\end{array}$ \\
\hline 1 & Vi sinh vật & 2 & 20 & 160 & 71,42 & 27 & 100 & 189 & 72,41 \\
\hline 2 & Độc tố tự nhiên & 8 & 80 & 7 & 3,12 & 0 & 0 & 15 & 5,74 \\
\hline 3 & $\begin{array}{l}\text { Hóa chất (thuốc } \\
\text { bảo vệ thực vật) }\end{array}$ & 0 & 0 & 57 & 25,44 & 0 & 0 & 57 & 21,83 \\
\hline & Tổng & 10 & 100 & 224 & 100 & 27 & 100 & 261 & 100 \\
\hline
\end{tabular}

Từ năm 2016 đến năm 2018, số người mắc NĐTP do độc tố tự nhiên giảm nhưng số người mắc NĐTP do vi sinh vật thì tăng. Tỷ lệ NĐTP do vi sinh vật chiếm tỷ lệ cao nhất $72,41 \%$ với 189 người mắc; thấp nhất là NĐTP do độc tố tự nhiên với 15 người mắc, chiếm tỷ lệ $5,74 \%$.

\section{3. Đối tượng mắc NĐTP tại tỉnh BR-VT giai đoạn 2016 - 2018}

Tỉnh BR-VT có nhiều lợi thế khai thác tiềm năng lĩnh vực dịch vụ và du lịch. Hàng năm, tỉnh đều đón và phục vụ trên 10.000.000 khách du lịch trong đó năm 2018 có khoảng 13.500 .000 khách du lịch. Do vậy, NĐTP ngoài việc xảy ra đối với cư dân tỉnh BR-VT thì còn xảy ra đối với khách du lịch.

Bảng 3. Tỷ lệ khách du lịch và người dân địa phuơng mắc NĐTP giai đoạn 2016 - 2018

\begin{tabular}{|c|c|c|c|c|c|c|c|c|c|}
\hline \multirow[b]{2}{*}{$S T T$} & \multirow[b]{2}{*}{$\begin{array}{c}\text { Đối tượng mắc } \\
\text { NĐTP }\end{array}$} & \multicolumn{2}{|c|}{2016} & \multicolumn{2}{|c|}{2017} & \multicolumn{2}{|c|}{2018} & \multicolumn{2}{|c|}{ Giai đoạn } \\
\hline & & $\begin{array}{c}\text { Số } \\
\text { người } \\
\text { mắc }\end{array}$ & $\begin{array}{l}\text { Tỉ lẹ } \\
\text { (\%) }\end{array}$ & $\begin{array}{c}\text { Số } \\
\text { người } \\
\text { mắc }\end{array}$ & $\begin{array}{l}\text { Tỉ lẹ } \\
(\%)\end{array}$ & $\begin{array}{c}\text { Số } \\
\text { người } \\
\text { mắc }\end{array}$ & $\begin{array}{l}\text { Tỉ lẹ } \\
\text { (\%) }\end{array}$ & $\begin{array}{c}\text { Số } \\
\text { người } \\
\text { mắc }\end{array}$ & $\begin{array}{l}\text { Tỉ lẹ } \\
\text { (\%) }\end{array}$ \\
\hline 1 & Khách du lịch & 00 & 00 & 70 & 41,91 & 27 & 100 & 97 & 47,55 \\
\hline 2 & Cư dân địa phương & 10 & 100 & 97 & 58,08 & 0 & 0 & 107 & 52,45 \\
\hline & Tổng & 10 & 100 & 167 & 100 & 27 & 100 & 204 & 100 \\
\hline
\end{tabular}

Theo số liệu Niên giám thống kê năm 2017, dân số tỉnh BR-VT là 1.101.647 người. Như vậy, lượng khách du lịch hàng năm đến tỉnh cao gấp khoảng 10 lần so với dân số của tỉnh. Tuy nhiên, kết quả nghiên cứu ở đây cho thấy tỷ lệ khách du lịch mắc NĐTP thấp hơn so với cư dân địa phương. Giai đoạn từ 2016-2018, số khách du lịch đến BR-VT mắc NĐTP là 97 người (chiếm tỷ lệ 47,55\%), số cư dân tỉnh BR-VT mắc NĐTP là 107 người (chiếm tỷ lệ 52,45\%).

Tỷ lệ khách du lịch mắc NĐTP thấp hơn so với cư dân địa phương là do chính quyền các cấp, các ngành cũng như các cơ sở kinh doanh dịch vụ ăn uống và lưu trú phục vụ du khách đã xác định việc đảm bảo ATTP trong lĩnh vực dịch vụ và du lịch là mục tiêu hàng đầu, trọng tâm.

\subsection{Phân bố vụ NĐTP tại tỉnh BR-VT theo huyện, thị thành}

Thành phố Vũng Tàu là địa phương có số vụ NĐTP và số người mắc cao nhất, tổng cộng 03 vụ với 103 người mắc, nguyên nhân NĐTP của 03 vụ đều do vi sinh vật. Đặc biệt tại huyện Xuyên Mộc xảy ra 02 vụ với 07 người mắc nhưng có 03 người tử vong, nguyên nhân NĐTP của 02 vụ đều do độc tố tự nhiên. Trong giai đoạn từ 2016-2018, huyện Châu Đức và huyện Đất Đỏ không xảy ra vụ NĐTP nào. 
Bảng 4. Phân bố vụ NĐTP tại tỉnh BR-VT theo huyện, thị thành giai đoạn 2016-2018

\begin{tabular}{|c|c|c|c|c|c|c|c|c|c|}
\hline$S T T$ & $\begin{array}{l}\text { Long } \\
\text { Điền }\end{array}$ & $\begin{array}{c}\text { Xuyên } \\
\text { Mộc }\end{array}$ & $\begin{array}{l}\text { Phú } \\
\text { Mỹ }\end{array}$ & $\begin{array}{c}\text { Vũng } \\
\text { Tàu }\end{array}$ & Bà Rịa & $\begin{array}{l}\text { Côn } \\
\text { Đảo }\end{array}$ & $\begin{array}{l}\text { Châu } \\
\text { Đúcc }\end{array}$ & $\begin{array}{l}\text { Đất } \\
\text { Đỏ }\end{array}$ & $\begin{array}{l}\text { Tổng } \\
\text { cộng }\end{array}$ \\
\hline Số vụ & 1 & 2 & 1 & 3 & 1 & 1 & 0 & 0 & 09 \\
\hline $\begin{array}{c}\text { Số } \\
\text { người } \\
\text { mắc }\end{array}$ & 5 & 7 & 29 & 103 & 57 & 3 & 0 & 0 & 204 \\
\hline $\begin{array}{c}\text { Số } \\
\text { người tử } \\
\text { vong }\end{array}$ & 0 & 03 & 0 & 0 & 0 & 0 & 0 & 0 & 03 \\
\hline $\begin{array}{l}\text { Nguyên } \\
\text { nhân } \\
\text { NĐTP }\end{array}$ & $\begin{array}{c}\text { Độc tố } \\
\text { tự nhiên }\end{array}$ & $\begin{array}{c}\text { Độc tố tự } \\
\text { nhiên }\end{array}$ & $\begin{array}{l}\text { Vi sinh } \\
\text { vật }\end{array}$ & $\begin{array}{c}\text { Vi sinh } \\
\text { vật }\end{array}$ & $\begin{array}{c}\text { Hóa } \\
\text { chất }+ \\
\text { vi sinh } \\
\text { vật }\end{array}$ & $\begin{array}{c}\text { Độc tố } \\
\text { tự nhiên }\end{array}$ & - & - & - \\
\hline
\end{tabular}

\subsection{Phân bố vụ NĐTP theo địa điểm ăn uống}

Bảng 5. Phân bố vu NĐTP theo địa điểm ăn uống giai đoạn 2016-2018

\begin{tabular}{|c|c|c|c|c|c|c|c|c|}
\hline \multirow{2}{*}{ STT } & \multirow{2}{*}{ Năm } & \multirow{2}{*}{ Tổng số vụ } & \multicolumn{2}{|c|}{ Gia dinh } & \multicolumn{2}{|c|}{ BATT } & \multicolumn{2}{c|}{ DVAU } \\
\cline { 4 - 9 } & & & Số vụ & Tỉ lẹ \% & Số vụ & Ti lệ \% & Số vụ & Ti lệ \% \\
\hline 1 & 2016 & 02 & 02 & 100 & 0 & 0 & 0 & 0 \\
\hline 2 & 2017 & 06 & 03 & 50 & 02 & 33,33 & 01 & 16,67 \\
\hline 3 & 2018 & 01 & 0 & 0 & 0 & 0 & 01 & 100 \\
\hline & Tổng & 09 & 05 & 55,56 & 02 & 22,22 & 02 & 22,22 \\
\hline
\end{tabular}

Năm 2016, địa điểm ăn uống xảy ra NĐTP tại các hộ gia đình chiếm tỷ lệ 100\% số vụ NĐTP. Năm 2017, cả ba địa điểm ăn uống đều xảy ra NĐTP, cụ thể là tại gia đình chiếm tỷ lệ $50 \%$, bếp ăn tập thể chiếm tỷ lệ 33,33\%, nhà hàng ăn uống (DVAU) chiếm tỷ lệ 16,67\%. Năm 2018, chỉ xảy ra NĐTP tại nhà hàng ăn uống, chiếm tỷ lệ $100 \%$ số vụ NĐTP.

\section{BÀN LUẬN}

\subsection{Các vụ NĐTP do độc tố tự nhiên}

Trong giai đoạn 2016-2018, tỉnh BR-VT chỉ có 03 huyện là Long Điền, Xuyên Mộc và Côn Đảo xảy ra NĐTP do độc tố tự nhiên, có tổng cộng 04 vụ với 13 người mắc và 02 người NĐTP riêng lẻ, số người tử vong 03 người. Nguyên nhân NĐTP do sử dụng thực phẩm có chứa độc tố tự nhiên như cá nóc, thịt cóc, nhộng ve sầu. Tỷ lệ trung bình NĐTP do độc tố tự nhiên của tỉnh BR-VT trong giai đoạn 2016-2018 là 1,33 vụ/năm, 4,33 người mắc/năm, số người tử vong 01 người/năm. Các vụ ngộ độc này xảy ra $100 \%$ ở các hộ gia đình, mỗi vụ tuy ít người mắc hơn so với nhóm NĐTP do vi sinh vật hoặc do hóa chất nhưng nguy cơ tử vong rất cao nếu không được cấp cứu kịp thời. Theo nghiên cứu của Nguyễn Hùng Long về Thực trạng NĐTP do độc tố tự nhiên tại Việt Nam giai đoạn 2010-2014, hàng năm, tại Việt Nam, trung bình có khoảng 40 vụ NĐTP do độc tố tự nhiên với trên 150 người mắc và 20 người tử vong. Tỷ lệ mắc NĐTP do độc tố tự nhiên thấp $(0,174$ người mắc/100.000 
dân/năm) nhưng có tỷ lệ tử vong/mắc cao $(13,4 \%)$ [10]. Như vậy, nghiên cứu của chúng tôi phù hợp và có số vụ, số người mắc và tỷ lệ tử vong/mắc thấp hơn so với nghiên cứu của Nguyễn Hùng Long.

Giai đoạn 2016-2018, toàn tỉnh xảy ra 01 vụ NĐTP với 03 người mắc và tử vong do độc tố cóc tại huyện Xuyên Mộc, tỷ lệ tử vong/mắc do độc tố cóc là $100 \%$. Tỷ lệ này cao hơn so với nghiên cứu của Nguyễn Hùng Long về Thực trạng NĐTP do độc tố tự nhiên tại Việt Nam giai đoạn 20102014 với tỷ lệ tử vong/mắc do độc tố cóc là $21,05 \%$ [10].

Nguyên nhân nhóm NĐTP do độc tố tự nhiên là do tâm lý chủ quan của người sử dụng, biết thực phẩm có độc tố tự nhiên nhưng vẫn ăn hoặc do thiếu sự hiểu biết. Phân tích của chúng tôi phù hợp với nghiên cứu của Phạm Thị Đan Phượng và Phan Thị Thanh Hiền về Thực trạng NĐTP do độc tố Tetrodotoxin ở Khánh Hòa cho thấy sự hiểu biết về đặc tính và độc tính của độc tố cá nóc chưa được người dân nắm bắt và quan tâm, chỉ $2,78 \%$ trong số họ có tìm hiểu qua tạp chí [14]. Nghiên cứu của Đỗ Đức Dũng và cộng sự năm 2012 về Thực trạng kiến thức về NĐTP của sinh viên Y2 trường Đại học Y Hà Nội cho thây kiến thức của sinh viên về NĐTP còn nhiều hạn chế, đa số mới dừng lại ở mức đúng nhưng chưa đủ. Tỷ lệ sinh viên có kiến thức đúng về NĐTP do thực phẩm có chất độc là $71,5 \%$ [3]. Điều này cho thấy trong cộng đồng dân cư, dù ở nhóm có trình độ dân trí cao hay thấp thì đều có các trường hợp không được trang bị kiến thức, không hiểu biết về NĐTP, đặc biệt là NĐTP do thực phẩm có độc tố tự nhiên.

\subsection{Các vụ ngộ độc do vi sinh vật}

Trong giai đoạn 2016-2018, toàn tỉnh xảy ra 05 vụ NĐTP do vi sinh vật với 189 người mắc (chiếm tỷ lệ $72,41 \%$ tổng người mắc), số người tử vong là 0 người. Tỷ lệ trung bình là 1,67 vụ/năm, 63 người mắc/năm, số tử vong 0 người/năm. Tỷ lệ NĐTP do vi sinh vật cao hơn so với tỷ lệ NĐTP do hóa chất, do độc tố tự nhiên. Nghiên cứu của Nguyễn Bảo Nhi về Khảo sát mức độ ô nhiễm vi sinh vật trong thực phẩm từ các mẫu thực phẩm xét nghiệm tại Trung tâm Y tế dự phòng tỉnh BR-VT cũng cho thấy trong 598 mẫu thực phẩm xét nghiệm thì có 255 mẫu không đạt về các chỉ tiêu vi sinh vật (chiếm tỷ lệ 47,63\% số mẫu) [12].

Nguyên nhân của nhóm NĐTP do vi sinh vật trên là do quá trình chế biến thực phẩm không bảo đảm ATTP. Kết luận nghiên cứu này phù hợp với nghiên cứu của các tác giả Nguyễn Phan Ái Hà, Lê Hoàng Ninh, Đoàn Lê Thanh Phong, Đặng Văn Chính về NĐTP do Salmonella ở một công ty may thuộc tỉnh Tiền Giang vào tháng 10 năm 2013, trong đó nguyên nhân gây nên sự nhiễm và phát triển của Salmonella vào thực phẩm là do quy trình chế biến, quá trình vận chuyển, quá trình bảo quản trong bếp ăn không bảo đảm [5].

\subsection{Vụ ngộ độc do hóa chất}

Trong giai đoạn 2016-2018, toàn tỉnh xảy ra 01 vụ NĐTP do hóa chất (món ăn nấm bào ngư xào cà rốt hành lá tồn dư thuốc bảo vệ thực vật) với 57 người mắc (chiếm tỷ lệ 21,83\% tổng số người mắc), số tử vong là 0 người. Tỷ lệ trung bình là 0,33 vụ/năm, 19 người mắc/năm, số tử vong 0 người/năm. Theo báo cáo tổng kết công tác VSATTP năm 2007 của Bộ Y tế, trung bình mỗi năm cả nước có tỷ lệ NĐTP do rau, củ, quả là 24 vụ/năm với 440,29 người mắc/năm; tỷ lệ NĐTP do hoá chất bảo vệ thực vật là 16,14 vụ/năm với 373,57 người mắc/năm [1]. Như vậy tỷ lệ NĐTP do hoá chất bảo vệ thực vật của tỉnh BR-VT so với cả nước chiếm $2,04 \%$ số vụ, $5,08 \%$ số người mắc.

Nguyên nhân của vụ NĐTP do hóa chất ở trên là do người trồng trọt không tuân thủ các quy định về liều lượng sử dụng, thời gian cách ly tối thiểu trước khi thu hoạch rau củ quả và sử dụng thuốc ngoài danh mục sử dụng cho rau, củ, quả. Kết quả nghiên cứu của Phan Thị Thu Hằng (2008) cũng cho biết tại Thành phố Thái Nguyên người trồng rau thường sử dụng thuốc bảo vệ thực vật có liều lượng cao gấp từ $1,5-2,0$ lần so với quy định, tính trên một lứa rau tổng số lần 
phun từ $3-10$ lần tùy theo loại rau, thời gian cách ly hầu hết chỉ từ $2-8$ ngày [6]. Nghiên cứu của Bùi Thị Nga và Lâm Quốc Việt năm 2010 cũng cho thấy hàm lượng thuốc trừ sâu vẫn còn lưu tồn trong rau xà lách xoong dao động trong khoảng $0,01 \mathrm{ppm}-0,05 \mathrm{ppm}$ (alphacypermethrin) và $0,23-0,99 \mathrm{ppm}$ (cypermethrin). Tỷ lệ hộ trồng rau sử dụng thuốc không theo liều lượng khuyến cáo chiếm 39,6\% [11]. Từ kết quả nghiên cứu của chúng tôi và một số tác giả ở trên cho thấy tỷ lệ sản phẩm rau củ quả không đảm bảo ATTP còn cao, vấn đề tồn dư hóa chất bảo vệ thực vật vẫn chưa được kiểm soát, đang là mối đe dọa gây ảnh hưởng tới sức khỏe và tính mạng người tiêu dùng.

\subsection{Phân bố vụ NĐTP theo địa điểm ăn uống giai đoạn 2016 - 2018}

Số vụ NĐTP xảy ra tại các gia đình là 05 vụ, chiếm tỷ lệ $55,56 \%$ số vụ; tại các bếp ăn tập thể là 02 vụ, chiếm tỷ lệ $22,22 \%$ số vụ; tại các nhà hàng ăn uống là 02 vụ, chiếm tỷ lệ $22,22 \%$ số vụ.

Trong giai đoạn 2016-2018, tỉnh Bà Rịa - Vũng Tàu không ghi nhận trường hợp NĐTP nào xảy ra tại đám cỗ cưới/đám giỗ và thức ăn đường phố. Tuy nhiên, tỷ lệ NĐTP tại các hộ gia đình, bếp ăn tập thể, các nhà hàng ăn uống lại cao hơn nghiên cứu của các tác giả sau:

Nghiên cứu Nguyễn Thùy Dương và cộng sự tại Hà Nội giai đoạn 2010-2014 với tỷ lệ phân bố vụ NĐTP tại các gia đình là $38,5 \%$, tại đám cỗ cưới là $38,5 \%$, tại bếp ăn tập thể là $15,4 \%$ và địa điểm ăn uống khác là 7,6\% [4];

Nghiên cứu Đoàn Lê Thanh Phong, tại Tiền Giang từ năm 2006 đến năm 2015 với 35,4\% vụ NĐTP xảy ra tại bữa ăn gia đình, 29,1\% tại tiệc cưới/giỗ và 24,1\% tại bếp ăn tập thể [13];

Nghiên cứu Bùi Quang Lộc và Trương Hữu Hoài, tại tỉnh Đắk Lắk từ 2004-2013 cho thấy có $55,8 \%$ vụ NĐTP xảy ra tại bữa ăn gia đình, 17,3\% tại tiệc cưới/giỗ, 9,6\% tại bếp ăn tập thể và 5,8\% thức ăn đường phố [9];

Nghiên cứu Lâm Quốc Hùng, trong toàn quốc từ 2002 đến tháng 9 năm 2007 cho thấy có 50,0\% vụ NĐTP xảy ra tại bữa ăn gia đình, 17,3\% tại tiệc cưới/giỗ, 11,5\% tại bếp ăn tập thể và $11,5 \%$ tương đương địa điểm ăn uống đối với thức ăn đường phố [7];

Địa điểm ăn uống của Bà Rịa - Vũng Tàu có tỷ lệ NĐTP cao nhất là tại các gia đình, chiếm tỷ lệ $55,56 \%$ số vụ NĐTP. Đặc điểm chung của các vụ NĐTP tại các hộ gia đình thường có số người mắc/vụ thấp (cao nhất là 06 người/vụ tại thành phố Vũng Tàu) nhưng có nguy cơ tử vong cao do phần lớn người dân có kiến thức về ATTP thấp, đặc biệt là hiểu không đúng, không đầy đủ về các loại thực phẩm có sẵn chất độc tự nhiên. Các hộ gia đình xảy ra NĐTP thường cư trú ở nơi có mật độ dân cư thưa, chủ yếu ở các vùng nông thôn do vậy cũng hạn chế trong việc tiếp xúc với các thông tin tuyên truyền về ATTP. Theo nghiên cứu Nguyễn Thị Huỳnh Mai và cộng sự cũng cho thấy: tại nơi có tỷ lệ đô thị hóa cao như TP. Hồ Chí Minh thì tỷ lệ người dân có kiến thức đúng phòng chống NĐTP vẫn còn hạn chế. Tỷ lệ người dân có kiến thức đúng các kiến thức về vệ sinh an toàn trong chế biến thực phẩm, kiến thức về bảo quản và sử dụng thực phẩm an toàn chỉ chiếm $19,4 \%$, thực hành đúng của người dân tại gia đình trong việc phòng chống NĐTP là 64,0\% [8].

\section{KẾT LUẬN}

Tình hình NĐTP tại tỉnh Bà Rịa - Vũng Tàu đã giảm so với các giai đoạn trước nhưng vẫn có xu hướng diễn biến phức tạp.Trong giai đoạn 2016-2018, toàn tỉnh xảy ra 09 vụ NĐTP và 02 người mắc riêng lẻ với tổng 204 người mắc và 03 người tử vong. Nguyên nhân gây NĐTP do vi sinh vật chiếm tỷ lệ $72,41 \%$ người mắc; do độc tố tự nhiên là $5,74 \%$; do hóa chất là $21,83 \%$. Tỷ lệ khách du lịch mắc NĐTP chiếm tỷ lệ $47,55 \%$ người mắc, người địa phương mắc chiếm tỷ lệ $52,45 \%$. Số vụ NĐTP xảy ra tại các gia đình chiếm tỷ lệ $55,56 \%$, tại các bếp ăn tập thể là $22,22 \%$, tại các nhà hàng ăn uống là $22,22 \%$. 
Để chủ động phòng chống, ngăn ngừa NĐTP xảy ra, các cơ quan quản lý nhà nước về ATTP cần tăng cường công tác truyền thông về ATTP đối với người tiêu dùng, người nội trợ và chủ cơ sở, người trực tiếp sản xuất, chế biến, kinh doanh thực phẩm; tăng cường công tác thanh tra, kiểm tra, giám sát về ATTP; công khai, đưa tin, tuyên truyền khách quan, trung thực, kịp thời về thực phẩm an toàn, nhất là các điển hình sản xuất, chế biến, lưu thông thực phẩm an toàn và đặc biệt là các vụ việc vi phạm ATTP; tiếp tục thực hiện giám sát mối nguy ô nhiễm thực phẩm, củng cố hệ thống cảnh báo nguy cơ NĐTP và các bệnh truyền qua thực phẩm.

\section{TÀI LIẸU THAM KHẢO}

1. Bộ trưởng Bộ Nông nghiệp và Phát triển nông thôn (2009), Đề án đảm bảo VSATTP rau, quả, chè và sản phẩm từ thịt giai đoạn 2009-2015 (Ban hành kèm theo Quyết định số 111 /QĐ-BNNQLCL ngày 14 tháng 01 năm 2009 của Bộ trưởng Bộ Nông nghiệp và Phát triển nông thôn), trang 19-21.

2. Chính phủ (2017), Báo cáo số 211/BC-CP ngày 19/5/2017 về tình hình thực thi chính sách, pháp luật về quản lý an toàn thực phẩm giai đoạn 2011-2016, trang 25.

3. Đỗ Đức Dũng và cộng sự (2012), "Thực trạng kiến thức về NĐTP của sinh viên Y2 trường Đại học Y Hà Nội”, Tạp chí Y học Cộng đồng, 2016 (Số 31, tháng 5/2016), trang 15.

4. Nguyễn Thùy Dương (2015), Trần Ngọc Tụ và Hoàng Đức Hạnh, "Tình hình NĐTP tại Hà Nội từ năm 2010 đến năm 2014”, Tạp chí Y tế công công, tập 10 số 37, trang 34-38.

5. Nguyễn Phan Ái Hà, Lê Hoàng Ninh, Đoàn Lê Thanh Phong, Đặng Văn Chính (2014), "Ngộ độc thực phẩm do Salmonella ở một công ty may thuộc tỉnh Tiền Giang vào tháng 10 năm 2013”, Tạp chi Y học TP. Hồ Chi Minh (Phụ bản Tập 18, Số 6, 2014), trang 428.

6. Phan Thị Thu Hằng (2008), "Nghiên cứu hàm lượng nitrat và kim loại nặng trong đất, nước, rau và một số biện pháp nhằm hạn chế sự tích lũy của chúng trong rau tại Thái Nguyên", Luận án Tiến sĩ Nông nghiệp, Đại học Thái Nguyên, 146 trang.

7. Lâm Quốc Hùng (2007), "Nghiên cứu một số đặc điểm dịch tễ học các vụ ngộ độc thực phẩm trong toàn quốc từ 2002 đến tháng 9 năm 2007", Kỷ yếu Hội nghị khoa học ATVSTP lần thư IV-2007, số 933+934, trang 213-217.

8. Nguyễn Thị Huỳnh Mai, Lê Hoàng Ninh và Trịnh Thị Hoàng Oanh (2016), "Kiến thức, thái độ, thực hành về phòng chống ngộ độc thực phẩm của người dân tại Tp. HCM năm 2013", Tạp chi Y học Tp Hồ Chi Minh, Chuyên đề Y tế công cộng, Tập 20. Số 1.

9. Bùi Quang Lộc, Trương Hữu Hoài (2014), "Tình hình gộ độc thực phẩm tại tỉnh Đắk Lắk từ 2004-2013", Tạp chí Y học thực hành, Hội nghị khoa học ATVSTP lần thứ VII-2014, trang 204-208.

10. Nguyễn Hùng Long (2016), “Thực trạng ngộ độc thực phẩm do độc tố tự nhiên tại Việt Nam giai đoạn 2010-2014", Tạp chí Y học dụ phòng, Tập XXVI, số 1 (174) 2016, trang 61-64.

11. Bùi Thị Nga và Lâm Quốc Việt (2010), "Hiện trạng sản xuất và lưu tồn thuốc trừ sâu trong đất, nước trên rau Xà lách Xoong tại xã Thuận An, huyện Bình Minh, tỉnh Vĩnh Long”, Tạp chí Khoa học 2010, Số 14, trang 278-287.

12. Nguyễn Bảo Nhi (2017), "Khảo sát mức độ ô nhiễm vi sinh vật trong thực phẩm từ các mẫu thực phẩm xét nghiệm tại Trung tâm Y tế dự phòng tỉnh Bà Rịa - Vũng Tàu từ 01/6/201631/5/2017", Kỷ yếu Các đề tài nghiên cứu khoa học, sáng kiến tham gia Hội nghị KHCN ngành Y tế tỉnh Bà Rịa -Vũng Tàu năm 2017, trang 319.

13. Đoàn Lê Thanh Phong (2016), "Đặc điểm dịch tễ các vụ NĐTP tại Tiền Giang từ năm 2006 đến năm 2015”, Tạp chi Y học TP. HCM, Phụ bản Tập 20, Số 05, 2016, trang 209-215.

14. Phạm Thị Đan Phượng và Phan Thị Thanh Hiền (2014), "Thực trạng NĐTP do độc tố Tetrodotoxin ở Khánh Hòa", Tạp chi Khoa học - Công nghệ thủy sản, số 03, trang 288. 


\section{Summary}

FOOD POISONING ASSESSMENT IN BA RIA - VUNG TAU, 2016 - 2018

\section{Tieu Van Linh, Dinh Thi Ngan}

${ }^{I}$ Department of Food Hygiene and Safety of Ba Ria - Vung Tau Province

Food poisoning could cause serious health issues. In this report, the statistical data about food poisoning available from 2016 to 2018 in Ba Ria - Vung Tau province was analyzed. The aim is to outline basic strategic action plans for addressing key factors that affected food safety in the region.

It was found that there were annually 03 cases of foodborne outbreaks with 68 infected people and 01 fatality. The most common causes of food poisoning were microorganisms $(72.41 \%)$, followed by chemical pesticides $(21.83 \%)$ and the least were natural toxins (5.74\%). Foodborne outbreaks normally occurred in residential kitchens $(55.56 \%)$, factory canteen $(22.22 \%)$, and restaurants $(22.22 \%)$.

Keywords: Food poisoning case, foodborne outbreaks, food safety, Ba Ria - Vung Tau province. 